\title{
APLICAÇÃO DE EXTRATO DE NIM (Azadirachta indica L.) EM TRIPES (Frankiliniella shultzei L.) NA CULTURA DO TOMATEIRO
}

\author{
Antônio Missiemário Pereira BERTINO ${ }^{1}$ \\ Mário Leno Martins VÉRAS ${ }^{2}$ \\ Aline Batista BELÉM ${ }^{3}$ \\ Rosinaldo de Sousa FERREIRA ${ }^{4}$ \\ Jacinto de Luna BATISTA ${ }^{5}$
}

\begin{abstract}
RESUMO: O tomate é cultivado mundialmente, com enorme relevância econômica. É a segunda hortaliça mais produzida e consumida no Brasil e no mundo, em que a maior parte da produção é consumida in natura e o restante processada industrialmente. É uma das culturas que mais apresentam praga que encarecem sua produção, invibializando seu cultivo. Uma das pragas é o tripes, onde as plantas atacadas apresentam os sintomas a partir do transplante, sendo que, para ser portador da virose, é necessário que o inseto se alimente da planta doente. Por serem considerados insetos-praga vetores de viroses, para o controle do tripes, recomenda-se a adoção que quando forem encontrados os primeiros insetos adultos no ponteiro da planta, utilizar técnicas de prevenção. Um dos métodos recentemente utilizado é através de extratos vegetais, a exemplo do nim, que reduzem o custo e o uso de agrotóxicos, contudo, há ainda carência de estudos a respeito de sua utilização.
\end{abstract}

Palavras-chave: tomaticultura, insetos pragas, controle de pragas

RESUMEN: El tomate se cultiva en todo el mundo, con gran importancia económica. Es la segunda hortaliza más producida y consumida en Brasil y en el mundo, donde la mayoría de la producción se consume fresco y el resto procesados industrialmente. Es una de las culturas que tienen más plaga que aumentan su producción, invibializando cultivo. Una plaga es trips, donde las plantas atacadas muestran síntomas después del trasplante, y para ser portadores del virus, es necesario que el insecto se alimenta la planta enferma. Debido a que son considerados insectos plagas vectores de enfermedades de virus, para el control de trips, se recomienda adoptar que cuando los primeros insectos adultos se encuentran en la parte de la planta, utilizando técnicas de prevención. Uno de los métodos utilizados recientemente es a través de extractos de plantas, tales como el neem, que reducen el coste y el uso de pesticidas, sin embargo, todavía hay una falta de estudios con respecto a su uso.

Palabras-chave: la producción de tomate, las plagas de insectos, control de plagas

\footnotetext{
${ }^{1}$ Graduação em Ciências Agrárias pela Universidade Estadual da Paraíba, Brasil(2014). missiemario1994@hotmail.com

${ }^{2}$ Mestrando em agronomia, Universidade Federal da Paraíba - UFPB/Campus II - Areia - Paraíba - Brasil. mario.deus1992@bol.com.br

3 allynebatista@hotmail.com

${ }^{4}$ rosinaldoagrarias@hotmail.com

${ }^{5}$ jacinto@ufpb.br
} 


\begin{abstract}
The tomato is grown worldwide, with huge economic importance. It is the second most produced and consumed vegetable in Brazil and in the world, where most of the production is consumed fresh and the remainder processed industrially. It is one of the cultures that have more plague which increase their production, invibializando cultivation. A pest is thrips, where the attacked plants show symptoms after the transplantation, and to be carrying the virus, it is necessary that the insect feeds the diseased plant. Because they are considered pest insects vectors of virus diseases, for the control of thrips, it is recommended to adopt that when the first adult insects are found in the hand of the plant, using prevention techniques. One of the recently used methods is through plant extracts, such as the neem, which reduce the cost and the use of pesticides, however, there is still a lack of studies regarding its use.
\end{abstract}

Keywords: tomato production, insect pests, pest control

No Brasil, a Tomaticultura tem grande importância econômica, com uma área plantada de 60.292 ha e produção anual de 3,7 milhões de toneladas (AGRIANUAL, 2009). É a segunda hortaliça mais produzida e consumida no pais e no mundo, sendo que a maior parte da produção é para o consumo in natura e o restante para o processamento industrial (FILGUEIRA, 2008).

O tripes Frankliniella schultzei L. (Thysanoptera: Thripidae) é um inseto que está presente em todos os continentes (CAB INTERNATIONAL, 2010), existem mais 500 espécies de plantas que de hospedeiras para esse inseto, pertencentes a 50 famílias, incluindo muitas culturas de importância agrícola, como feijão, pimentão, pepino, berinjela, alface, cebola, tomate, melancia e ornamentais (YUDIN et al., 1986; MONTEIRO et al., 2001; DAISIE, 2006; CAB INTERNATIONAL, 2015).

O gênero Frankliniella é representado por muitas espécies, tendo importância agrícola, pois algumas são vetores de vírus em plantas Podem ser facilmente reconhecidos pelas antenas de oito artículos, os dois últimos menores e afilados; insetos de cor clara ou escura; duas cerdas intercalares desenvolvidas; uma cerda pós-ocular desenvolvida; um par de cerdas bem desenvolvido na margem de cada quadrante do protórax e duas nervuras com cerdas equidistantes em quase toda a extensão da asa anterior (ROSSETTO et al., 1974).

A fase de ovos dura cinco dias e em seguida, eclodem, dando origem à ninfas, que duram em média três dias. Devido sua metamorfose incompleta ocorrem duas fases larvais que duram dois dias, seguidas da fase de pré-pupa e pulpa, que duram cinco dias chegando enfim na fase adulta. A duração das diversas fases de seu desenvolvimento pode variar conforme fatores ambientais. Em geral, o ciclo de vida do $F$. Schultzei dura em torno de 15 
dias. Os insetos adultos podem durar de 14 a 21 dias (PICANÇO, 2010).

Os tripes por serem considerados insetos-praga vetores de viroses, recomenda-se a adoção de medidas de controle quando forem encontrados os primeiros insetos adultos no ponteiro da planta. $\mathrm{O}$ controle dos tripes deve ser realizado de forma integrada, utilizando-se de diversas táticas preventivas de controle. Deve-se priorizar, portanto, à produção de mudas em viveiros localizados longe dos campos de produção e protegidos por telas tipo antiafídeos que não permitam a entrada dos tripes (MOURA, 2013).

Os extratos de plantas têm sido utilizados para o controle de pragas, substituindo o uso frequente de agrotóxicos sintéticos, pois tem contribuído para a redução de custos de produção das lavouras, riscos ambientais e dependência dos inseticidas convencionais (VIANA et al., 2003)

Há muito tempo a utilização de plantas inseticidas no controle de pragas agrícolas vem sendo usada, ante do surgimento dos inseticidas sintéticos essas espécies eram usadas comumente em países tropicais para o controle de pragas. Entretanto, com o aumento dos problemas causados pelo uso excessivo e indiscriminado de inseticidas organossinteticos como as contaminações ambientais, aparecimento de insetos resistentes, entre outros fatores adversos, aumentou-se o numero de pesquisas relacionadas à utilização de produtos oriundos de extratos e óleos vegetais no controle de pragas durante os últimos anos (BRUNHEROTTO; VENDRAMIM, 2001; MARTINEZ; VAN EMDEN, 2001; BOGORNI; VENDRAMIM, 2003; VIEGAS JÚNIOR, 2003; BOIÇA JÚNIOR et al., 2005; SOUZA; VENDRAMIM, 2010; TORRES et al., 2006).

O óleo de nim, extrato provindo de plantas da espécie Azadirachta indica L., que pertence à família Meliaceae, originária do sudeste da Ásia e cultivada em diversos países da África, Austrália, América do Sul e Central, tem sido destacada como importante produto no controle de pragas (MARTINEZ, 2002).

O extrato de nim (Azadirachta Indica L.) funciona como fungicidas e inseticidas, além de não ser tóxico a vertebrados (MARTINEZ, 2002). Estudos nos últimos anos mostra que o extrato de nim tem sido muito eficaz no controle de pragas responsáveis por grandes perdas nas culturas agrícolas.

\section{REFERÊNCIAS BIBLIOGRÁFICAS}


AGRIANUAL. Anuário da agricultura brasileira. São Paulo: Instituto FNP, 2009. 497p.

BOGORNI, P. C., VENDRAMIM, J. D. Bioatividade de extratos aquosos de Trichilia spp. sobre Spodoptera frugiperda (J. E. Smith) (Lepidoptera: Noctuidae) em milho. Neotropical Entomology, Londrina, v. 32, n. 4, p. 665-669, 2003.

BOIÇA JÚNIOR, A. L., MEDEIROS, C. A. M., TORRES, A. L., CHAGAS FILHO, N. R. Efeito de extratos aquosos de plantas no desenvolvimento de Plutella xylostella (L.) (Lepidoptera: Plutellidae) em couve. Arquivos do Instituto Biológico, São Paulo, v. 72, p. 45-50, 2005.

BRUNHEROTTO, R., VENDRAMIM, J. D. Bioatividade de extratos aquosos de Melia azedarach L. sobre o desenvolvimento de Tuta absoluta (Meyrick) (Lepidoptera: Gelechiidae) em tomateiro. Neotropical Entomology, Londrina, v. 30, n. 3, p. 455- 459, 2001.

CAB International. Distribution Maps of Plant Pests. Disponível em: http://www.cabi.org/dmpp/default.aspx . Acesso em: 26/05/2015.

DAISIE (Delivering Alien Invasive Species Inventories for Europe). Last updated: 2006. Disponível em: <http://www.europealiens/org/speciesFactsheet.do?speciesId=51119>. Acesso em: 8/05/2015.

FILGUEIRA, F. A. R. Novo Manual de Olericultura: agrotecnologia moderna na produção e comercialização de hortaliças. 3.ed.Viçosa: UFV, 2008. 421p.

MARTINEZ, S. S. O Nim - Azadirachta indica: natureza, usos múltiplos, produção. Londrina: Instituto Agronômico do Paraná, 2002. 142p.

MARTINEZ, S. S., VAN EMDEN, H. F. Growth disruption, abnormalities and mortality of Spodoptera littoralis (Boisduval) (Lepidoptera: Noctuidae) caused by azadirachtin. Neotropical Entomology, Londrina, v. 30, n. 1, p. 113-125, 2001.

MARTINEZ, S.S. O nim - Azadirachta indica - Natureza, usos múltiplos, produção. Londrina: IAPAR, 2002, 142 p.

MONTEIRO, R.C.; MOUND, L.A.; ZUCCHI, R.A. Espécies de Frankliniella (Thysanoptera: Thripidae) de Importância Agrícola no Brasil. Neotropical Entomology, v.1, p.65-72, 2001.

MOURA, A.P.; FILHO, M. M.; GUIMARÃES, J.A.; AMARO, G. B.; LIZ, R.S. Manejo integrado de pragas de pimentas do gênero Capsicum, Brasília-DF 2013.14p.

PICANÇO, M.C. Manejo Integrado de Pragas. Universidade Federal de Viçosa, ViçosaMG, 2010, 144p.

ROSSETO, C. J.; SANTIS DE L.; FILHO PARADELLA, O.; POMPEU, A. S. Espécies de Tripes coletadas em culturas de feijoeiro. Bragantia. v. 33. n. 3. p.9 - 14, 1974.

TORRES, A. L., BOIÇA JÚNIOR, A. L., MEDEIROS, C. A. M., BARROS, R. Efeito de extratos aquosos de Azadirachta indica, Melia azedarach e Aspidosperma pyrifolium no desenvolvimento e oviposição de Plutella xylostella. Bragantia, Campinas, v. 65, p. 447-457, 2006. 
VENDRAMIM, T. C. BOIÇA JUNIOR, A. L.; GHAGAS FILHO, N. R. Aspectos biológicos de Plutella xylostella (Lepidoptera: Plutellidae) em nove genótipos de repolho (Brassica oleracea VAR capitata). Revista de Agricultura, Piracicaba, v. 85, p. 117-126, 2010.

VIANA, P.A.P.; TEIXEIRA, H. Desenvolvimento e mortalidade larval de Spodoptera frugiperda em folhas de milho tratadas com extrato aquoso de folhas de Azadirachta indica. Bragantia, São Paulo, v.62, n.1, p. 69-74, 2003.

VIEGAS JÚNIOR, C. Terpenos com atividade inseticida: uma alternativa para o controle químico de insetos. Química Nova, São Paulo, v. 26, n. 3, p. 390-400, 2003.

YUDIN, L.S; CHO, J.J.; MITCHELL, W.C. Host range of western flower thrips, Frankliniella occidentalis (Thysanoptera: Thripidae), with special references to Leucaena glauca. Environmental Entomology, v.15, p.1292-1295, 1986. 